\title{
Introducing Learning Creative Mathematical Activity for Students in Extra Mathematics Teaching
}

\author{
Introducción al aprendizaje creativo de actividades matemáticas para \\ los estudiantes de enseñanza adicional
}

\author{
Anvar N. Khuziakhmetov* \\ Pavel M. Gorev ${ }^{* *}$
}

\begin{abstract}
The objective of the research is determined by the need to introduce creative learning mathematics activities for school students, because that is one of the ways of ensuring the effective acquisition of knowledge at the intersubject level and further successful adaptation while choosing a future career. Moreover, the resources of extra mathematics teaching at a general secondary school can be widely used. Thus, the purpose of the research is a) studying the theoretical basis for stimulating creative learning mathematics activities for the students and $b$ ) developing the teaching techniques of this stimulation in extra mathematics teaching at general secondary schools. The leading methods are a) modeling the task systems ensuring the development of the five types of learning activities: reproductive, productive, research, project, and project-research and b) the system analysis of the selections of experimental data based on estimating three criteria: fluency - the ability to generate a lot of ideas; flexibility - the ability to produce different ideas; ingenuity - the ability to react unconventionally. The experimental research has been carried out since 2001 and the problem systems characteristic of the five types of learning activities have been used. Subsequently, methodological approaches in extra mathematics teaching have been developed introducing creative mathematics activities for students.
\end{abstract}

Keywords: Extra mathematics teaching. Learning mathematics activities. Creative learning mathematics activity. Research activities of students. Project mathematics activities. Inter-subject connections.

\section{Resumen}

La actualidad de la investigación está determinada por la necesidad de introducir un aprendizaje creativo en las actividades matemáticas para los estudiantes de las escuelas, porque es una de las formas de asegurar la adquisición efectiva de conocimientos a nivel inter-sujetos y una adaptación más exitosa al elegir la futura carrera. Además, porque los recursos adicionales de enseñanza de matemáticas, en la escuela secundaria, pueden ser ampliamente utilizados. El objetivo de la investigación es estudiar la base teórica de estimulación del aprendizaje creativo de las actividades matemáticas en los estudiantes, y desarrollar las técnicas didácticas de su estimulación en la enseñanza adicional de matemáticas en la escuela secundaria. Los métodos principales son: a) modelación de sistemas de tareas que aseguren el desarrollo de los cinco tipos de actividades de aprendizaje (reproductivo, productivo, investigativo, de proyecto y proyectivo-investigativo), b) análisis sistémico de la selección de datos experimentales, basado en la estimación de tres criterios: fluidez en la capacidad de generar muchas ideas, flexibilidad de producir ideas diferentes e ingenio para reaccionar de forma no convencional. La investigación experimental se ha desarrollado desde el 2001, utilizándose los sistemas de problemas característicos de los cinco tipos de actividades de aprendizaje. Posteriormente, los enfoques metodológicos en la enseñanza adicional de matemáticas han sido desarrollados por la introducción de actividades de matemáticas, creativas, para los estudiantes.

\footnotetext{
* Doctor of Education, Professor of the Institute of Psychology and Education, Kazan (Volga region) Federal University, 420008, 18 Kremlyovskaya Street, Kazan, Russia. E-mail: hanvar9999@mail.ru.

** $\mathrm{PhD}$, Associate Professor of the Department of Fundamental and Computer Mathematics, Vyatka State University, 610000, 36 Moscovskaya Street, Kirov, Russia. E-mail: pavel-gorev@mail.ru.
} 
Palabras claves: Enseñanza adicional de matemáticas. Aprendizaje de actividades matemáticas. Aprendizaje creativo de actividades matemáticas. Actividad investigativa de estudiantes. Proyecto de actividad matemáticas. Conexiones entre sujetos.

\section{Introduction}

In the postindustrial era, intelligent systems and high technologies are becoming main values. Research in applied sciences such as medicine, biochemistry, geophysics, electronics, etc., is getting more significant. Their implementation into human activity requires proper changes in the educational system. Its recent innovation processes aim at developing an individual who is capable of adapting to the changing environment, finding solutions for new problems, processing available information to get only the vital things necessary for productive work, unconventional thinking, and acting. Based on the above mentioned, the following point should be added to the purposes of general education: developing an all-round creative personality capable of reaching full potential in dynamic socio-economic conditions (Development Concept of Mathematical Education in the Russian Federation, 2013).

It is hard to achieve this purpose, because the amount of mathematical information increases but the time to acquire it decreases. Thus, there is a need for finding new ways to achieve it. On the one hand, we can use extra mathematics teaching, on the other hand, we can apply practice-oriented problems realizing inter-subject and between-the-subject connections with applied sciences and ensuring students' readiness for finding solutions to vital problems and transforming reality in their creative learning activities.

The matter of introducing creative learning mathematics activities for school students is coming at an opportune time. The distinction between performing and creative activities is quite difficult: both suppose that a student acquires new knowledge and skills and it's the focus of any learning activity (Ibragimov et al., 2016). However, acquiring new knowledge and skills is not always creative and interesting for students.

Thus, the problem of developing creative learning mathematics activities in students is not properly studied in conditions of extra mathematics teaching at general secondary schools. There is a contradiction between the considerable potential of creative learning mathematics activities and the improper development of theoretical and methodological bases of its stimulation in extra mathematics teaching at general secondary schools.

Consequently, the problem of the research is finding more effective ways to develop creative learning mathematics activities in extra mathematics teaching. 


\section{Materials and methods}

\subsection{Research Methods}

The following methods were used to carry out the research: the analysis of governing documents, psychological, pedagogical, mathematical, and methodological literature on the research, the analysis and summarizing the existing teaching experience of extra-curricular math activities at school, the analysis of results from the learning activities, the method of the mental experiment, forecasting, classifying, and summarizing facts and concepts, modeling, projecting, the method of expert assessment, the analysis of results from the teaching activities, working out and applying educational learning materials in extra mathematics teaching, diagnostic techniques, the pedagogical experiment.

\subsection{The experimental base of the research}

Evaluation and introduction of the research results was carried out and are still being carried out at the experimental teaching and learning processes, in reports and at scientific conferences and seminars, in collections of scientific articles and methodological periodicals.

Pilot testing was conducted during the evaluation of the teaching methods in extra mathematics teaching at general secondary schools:

- at math study groups, specialized courses, and seminars for 5-9-form students using the authors-created materials (Gorev \& Utemov, 2014) at educational establishments (about 3,000 people annually, since 2006);

- at the summer mathematics camp "Mathematics. Creativity. Intelligence" for 5-8form students (annually since 2001 - about 150 people in the session).

Students of all school-age groups took part in the pilot testing from Kirov and Kirov region and from some schools in other Russian regions.

\subsection{The stages of the research}

The first stage revealed the problem in theoretical and practical teaching in extra mathematics teaching and the following methods have been used: a) the study and analysis of psychological, pedagogical, mathematical, and methodological literature on the research; b) the examination and analysis of the Math teaching experience to study the role, place, and 
ways of the effective development learning creative mathematics activity in extra mathematics teaching.

The second stage refined the theory and concept of developing creative learning mathematics activities in extra mathematics teaching: forming the content and organization of students' learning activities, defining and classifying its types, designing the method system, clarifying the role and position of creative mathematics activities in it.

The third stage outlined the most effective ways of developing learning creative mathematics activity in extra mathematics teaching. To fulfill the extra-curricular classes, Math activities were conducted in 5-9-form students in Kirov schools number 21, 27, 41, 46, 52, 57, a school-based summer mathematics camp for 5-8-form students was established and is still open in Kirov lyceum number 21.

The fourth stage conducted an educational experiment to check the work effectiveness of the suggested teaching methods. The results of the research were analyzed and processed by means of mathematical statistics.

\subsection{The description and analysis of the educational experiment results}

While performing the pilot testing, the specific character of the work in extra mathematics teaching was crucial. The educational organizations holding experimental work has the existing effective system of additional mathematical education, which includes the work of the mathematical study group. The system promotes the students' high motivation for work within the additional mathematical programs. The external challenges of defining the conditions which are not subject to any modifications during the experiment, difficulties in managing the process of developing creative activities and in selecting the criteria of its development level ensured the diagnostics of introducing creative activities for students. The 7-8-form students were divided into two groups - control and experimental ones. All 7-8-form students took part in the experiment. The experimental group included students who had attended the mathematical study group for a year, took part in competitions, and went to summer camp. Students attended the mathematical study group optionally, following their own choice and wish to study Math. The control group consisted of students who had never been engaged or had been engaged for a short time in extra mathematics teaching. The number of students in both groups was approximately the same.

To estimate the effectiveness of the suggested teaching methods introducing creative activities for students in extra mathematics teaching, three important creative criteria were 
diagnosed. In G. Gilford's (Gilford, 1965) opinion, they are the leading criteria for measuring creative activities for students. They are fluency - the ability to generate a lot of ideas; flexibility - the ability to produce different ideas; ingenuity - the ability to react unconventionally. To diagnose them, we selected the two equivalent variants (one - at the beginning, the other - at the end of the experiment) of the Gilford test measuring the creativity level in students.

The process and analysis of the results of the pilot testing were performed according to the following scheme. First, we compared the average results of the studied criteria (fluency, flexibility, ingenuity) in each problem out of five at the beginning and at the end of the experiment. Using the sign test criterion, we determined the effect of the applied teaching methods introducing creative activities for students on stimulating each creativity criterion in students. Then, using the multivariate statistical analysis, we revealed the effect of the applied teaching methods on stimulating general creativity in students.

Statistical data processing for the pilot testing suggested significant differences in general creativity in students of the experimental group before and after the experiment. The analysis of the research results with the sign test criterion revealed a higher level of general creativity in students after the experiment. In the control group, there were no significant changes in the criteria of creative mathematics activities.

Considering the data of all the conducted research and the result analysis, one can say that the suggested teaching methods developing creative mathematics activities in extra mathematics teaching has a dramatic effect on the change of creative activities criteria in students and that it improves them.

\section{Results}

The article does not focus on the psychological-and-pedagogic aspects of educational process and organizational forms of students' cognitive activities, because it needs a separate discussion. The article deals with the content of creative learning mathematical activities.

The research considered two criteria for the learning activities - the content and organization (Gorev, 2012; Kamalova \& Raykova, 2016). The content is understood to be certain knowledge, skills, algorithms, and techniques used in the activities. The organization is understood to be the order of regulating these activities components. The organization is a bit more extended, not developed algorithm or technique of the activity consisting of smaller, developed components. 
In this connection, the content and organization may have a strict regulation by teachers. As a rule, it is applied in the traditional mathematics teaching method: the order of learning information, its content, main techniques, and algorithms are provided in the educational standard textbooks and are always available for the students.

Our approach to the content and organization considers the role of the students in their choice. In this context, this is about the students' needs and motives, their active part in the learning process. Extending the choice of the content and organization beyond the subject topic and the subject itself implements the creative approach to learning Math.

Thus, combining the content and organization according to the degree of the freedom of choice, there are the following five types of student's learning activities (Table 1).

Table 1 - Types of the student's learning activity

\begin{tabular}{lll}
\hline \multicolumn{1}{c}{$\begin{array}{c}\text { Content of the learning } \\
\text { activity }\end{array}$} & Readily available & \multicolumn{2}{c}{ Organization of learning activity } \\
Student's choice
\end{tabular}
Source: Prepared by the author

1. Reproductive and productive learning activities are characterized by the lack of free choice for the content and organization of the activity. Both activities are provided in the academic program and regulated by the teacher. While forming the reproductive learning activity, the student must directly apply knowledge (concepts and facts) and skills (main techniques and algorithms). At this stage, the student must reproduce the definitions of basic terms, identifying definite objects, consciously reproducing statements of theorems, knowing and applying basic algorithms and techniques for the activity.

The problems of the productive learning activity are aimed at applying the knowledge and skills developed at the reproductive stage in another learning situation. At this stage, students are to solve mathematical problems. The problem situation does not fully contain familiar action algorithms, but reduces to them.

Mathematical model formation of a real practical problem is an example of such a reduction.

Problem 1. 8 liters of pure water is added into 2 liters of a $10 \%$ acetic acid solution. Find the percentage of acetic acid in the solution.

This problem can be solved by applying two algorithms, one after the other (the model is two numeric expressions): calculating the percentage (to learn how much 'pure' acetic acid is contained in the solution) and calculating the percentage of the other number. Obviously, 
while modeling, there are a lot of opportunities for solving practical problems. Inter-subject connections can be seen at this level.

Acquiring basic knowledge and skills in the matter under investigation at the stage of reproductive and productive learning activities completes the teaching process with the techniques stimulating the students' freedom to choose the content or organization of the learning activity (Şandır, \& Aztekin, 2016).

2. Offering free choice for the learning activity content ensures a new type of learning activity - the research activity. The student is a researcher, he applies the acquired knowledge and skills in new conditions: in other Math topics (inter-subject connections), in other school subjects (between-the-subject connections). This results in completing the finished activity structure with new content. It means making and solving new problems where the familiar algorithm is in a new learning situation. This process has some creative features because a new product is created for the student. I have identified two approaches for constructing the system of creativity-oriented problems when developing the research activity.

As a rule, in the first approach, the new content of the familiar organization is selected from the branches of Math or other neighboring subjects. Thus, inter-subject and between-thesubject connections in Math teaching are realized.

As the example of such organization in the research activity, let's describe the application of the algorithm realizing complete graph enumeration when solving different problems.

1) When calculating combinatorics and probability theories, the content regency is characterized by acquiring new information from these branches and interpreting the problems occurred on graphs.

Problem 2. There are three black balls and one white ball in the drawer. Two balls are taken out at random. What is the probability of taking out 1) two black balls; 2) one white and one black ball?

Solution. A probable outcome is the vertex of the graph, the order of outcomes is the rib of the graph. Then, the graphs of all probable outcomes are drawn (fig. 1).

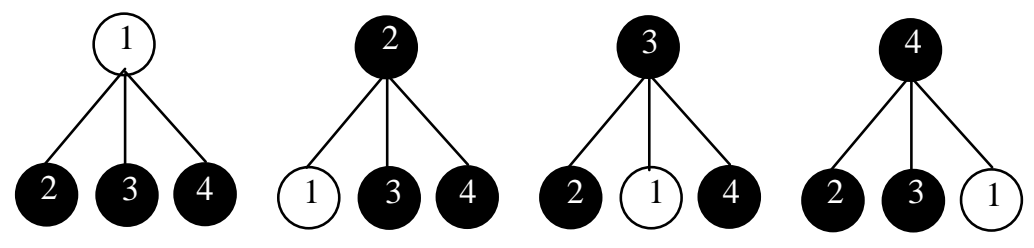

Figure 1 - Busting graph to the problem 2

Source: Prepared by the author 
For better visualization, the vertices of the graph are enumerated according to the ball number and marked with a corresponding color. Now, the pendant vertices of the branches are counted: they are 12. For situation 1) 6 outcomes are favorable. So, the probability of taking out 2 black balls is $6 / 12=1 / 2$. For situation 2 ) there are also 6 favorable outcomes and the probability is $1 / 2$.

2) The algorithm realizing complete graph enumeration is applied in solving strategydeveloping problems. Classical deterministic games, problems in flowing over, crossing, sharing, etc. are referred to them. Usually, such problems are solved mentally and require quick thinking. To find at least one solution to the problem is not difficult. To find the shortest solution or all the solutions is much more difficult.

Problem 3. Two people have a full 8-liter jar of milk and two empty 3-liter and 50liter jars. How can they share the milk equally?

The content novelty of this problem is marking each vertex of the graph as a code for filling the jars - ordered number triple: first - 8-liter, second - 5-liter, third - 3-liter (fig. 2). In this graph, there are no vertices with the same code (except for the last one which is being drawn into two for more visualization while selecting the length of enumeration).

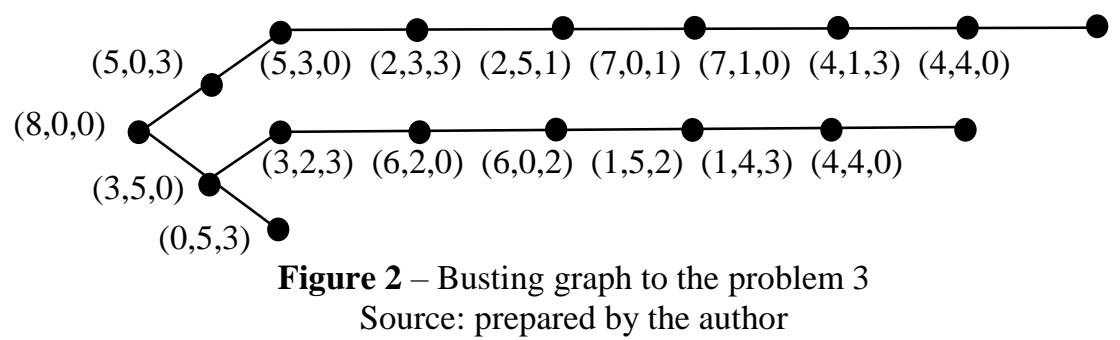

Thus, different content lines allow us to study the application of one or several algorithms and general action methods in new problems. Similar application variants are first selected by the teacher. Then, he asks the students to find familiar algorithms in new situations, develop and study new concepts and facts.

In the second approach, a new content of the familiar organization may be interpreted as the application of the familiar action algorithm in a less familiar situation. Here is the example.

Problem 4. Is it possible to walk in the park and its surroundings (fig. 3) so that to get over each fence only once? 


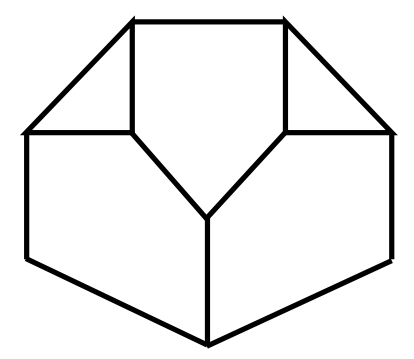

Figure 3 - Driving par Source: Prepared by the author

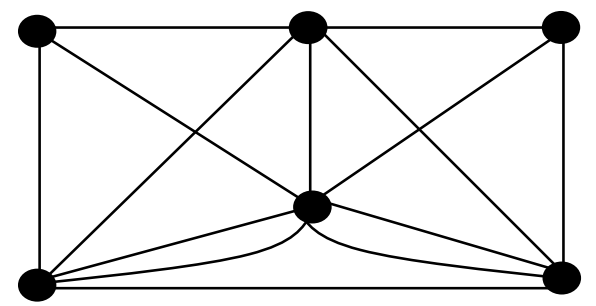

Figure 4 - Graph communication areas of the park Source: Prepared by the author

Here students have difficulties defining the vertices and ribs of the graph which are necessary for solving the problem. The vertices are to be considered as the areas of the surface divided by fences, the ribs - as the fence crossings. Experience has proven that such an approach to defining the vertices and ribs is very complicated for students and only a few can do that on their own. But having seen the constructed graph (fig. 4), students can quickly solve the problem as they can apply the familiar fact - the Euler rule for finding the graph cycle and paths. Obviously, there is no such path. So, it is impossible to meet the problem conditions.

Such problems are useful for gaining the experience of creative activities, as they stimulate unconventional thinking and the ability to find a familiar algorithm in a new situation.

Thus, the research activity is aimed at solving different problems, including practical ones. Such problems have no sufficient novelty in the activity organization and their content are either adjusted to the algorithm or hidden to some extent so that it can be found in a new learning situation.

3. If a student is given freedom of choice for the learning activity organization (i.e. the order of applying familiar algorithms and their components), it will be transformed into the project learning activity. The student starts his/her work studying the familiar content with applying new algorithms or their combinations. This results in finding new algorithms in a familiar learning situation or solving the set problems in a different way. This process has creative features.

We developed two approaches for constructing the system of creativity-oriented problems forming the project activity.

The first approach offers to find alternative solutions to problems on the topic. Obviously, students are to be taught to find them. The classes "One problem - different 
solutions" are very useful and they show various connections between branches and topics in Math. Here is the example.

Problem 5. Three friends are wearing white, red, and blue dresses. Their shoes are the same colors. Tamara's colors of the dress and shoes match. Valya is wearing white shoes. Lida's is wearing neither red dress nor red shoes. Identify the color of the dresses and shoes of each girl. This problem has the following graph solution.

Solution 1. Draw three multitudes: the multitude of friends, the multitude of their dresses and the multitude of their shoes. Draw full lines (if any matching) and dotted lines (if no matching) of the graph rib meeting the problem condition (fig.5a). The answer is to be in the form of three full line triangles with no vertex-sharing. Lida is to be wearing blue shoes (the $b$ vertex is taken, to the $r$ vertex - a dotted line) and no blue dress. Tamara is to be wearing red shoes and a red dress. So, Lida is to be wearing a white dress and Valya - a blue one (fig. 5b).

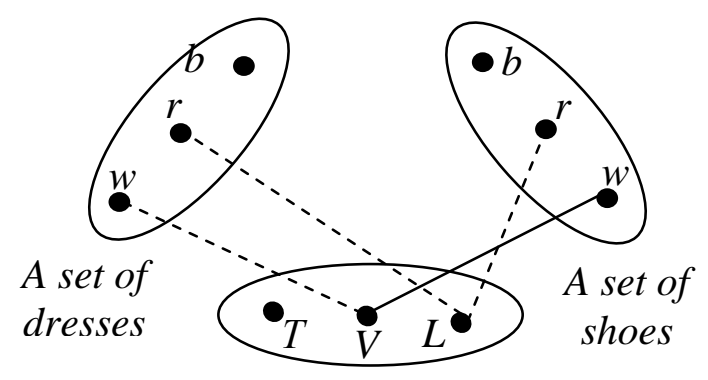

A set of friends

a)

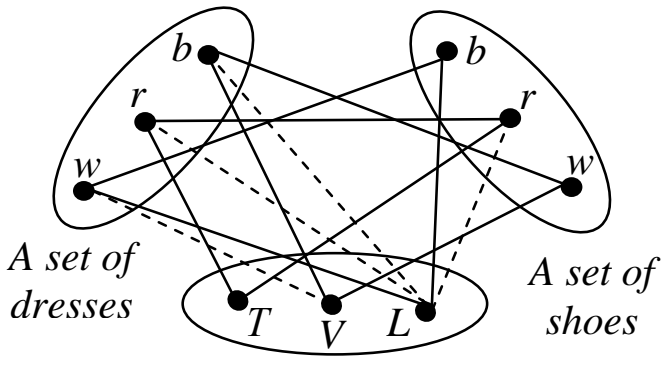

A set of friends

b)

Figure 5 - Graph links to problem 5

Source: Prepared by the author

While solving this problem the method of extensive trials and tabling are used. These tables are often square, that's why they are called 'logical squares'. If the problem deals with the values of two variables, one logical square is enough (double entry tables). Sometimes to solve the problem one needs more than one square. Thus, to solve this problem, two logical squares are to be drawn. Here, the true statement is marked as number 1, the false one - as number 0 .

\begin{tabular}{|c|c|c|c|c|c|c|}
\hline \multicolumn{3}{|c|}{ Dresses } & & \multicolumn{3}{|c|}{ Shoes } \\
\hline white & red & blue & & white & red & blue \\
\hline 0 & 1 & 0 & Tamara & 0 & 1 & 0 \\
\hline 0 & 0 & 1 & Valya & 1 & 0 & 0 \\
\hline 1 & 0 & 0 & Lida & 0 & 0 & 1 \\
\hline
\end{tabular}

Frame 1 - Solution 2: Logical squares for this problem are to be as follows.

Source: Prepared by the author 
Complete the squares. According to the condition, Valya is wearing white shoes (1) and, hence, no white dress (0). Lida's is wearing neither red dress nor red shoes (0). As each girl has only one pair of shoes and one dress, each line and each column of each square is to have one number 1 . Hence, the first column and the second line of the second square are to be completed. So, Tamara is wearing red shoes, Lida - blue ones. And Tamara is wearing a red dress and Lida - no blue one. Again, having added number 0 to the lines and columns of the square with numbers 1, one can see that Valya's dress is blue and Lida's one is white.

In the second approach, the construction of the problem system is based on selecting the problems with familiar content but requiring new content ideas. Here is the example.

Problem 6. In a society, any two friends have no mutual acquaintances, and any strangers have two mutual acquaintances. Prove that in this society everyone has equal number of acquaintances.

Solution. As a rule, the members of the society are graph vertices, acquaintances are graph ribs. The condition (1) "any two friends have no mutual acquaintances" means that the graph has no "triangles", i.e. no vertices mutually connected with the ribs. The condition (2) "any strangers have two mutual acquaintances" means that any vertices not connected with the rib relate to two ways of two ribs.

First, one needs to prove that two friends, A and B, have an equal number of friends (fig. 6a). According to the condition (1), all of A's friends are not familiar to B and B's friends are not familiar to A. Hence, according to the condition (2) each couple (A, B) is to have two mutual acquaintances. One of them is $\mathrm{A}$, the second is to be out of B1, B2, .. Bm. It means that each A1 is familiar to the one out of B1, B2, .. Bm. Here, it is impossible that Ai and Aj are familiar to Bk (fig. 6b) because, in this case, unfamiliar to each other, A and Bk are to have three mutual acquaintances $\mathrm{Ai}, \mathrm{Aj}$ and $\mathrm{B}$. So, each A's friend is familiar to one B's friend and vice versa. That's why, there are equal numbers.

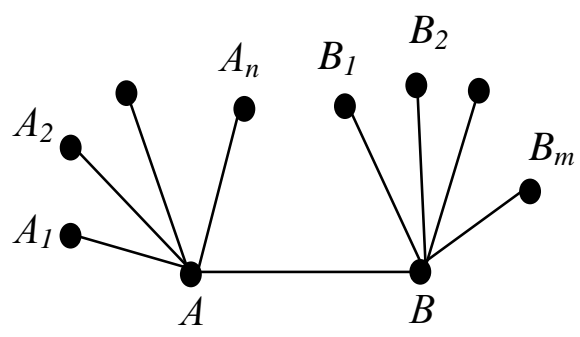

a)

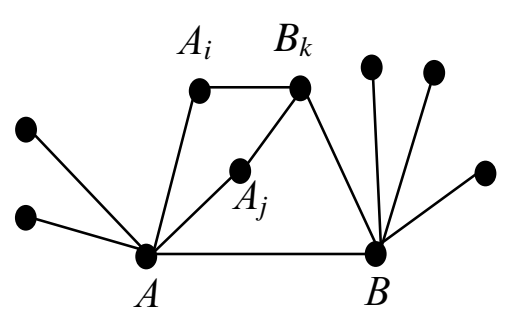

б)

Figure 6 - Visualization of solving the problem 6 Source: Prepared by the author 
Now take two strangers, $\mathrm{A}$ and $\mathrm{C}$, and find their mutual acquaintance B. A and B, B and $\mathrm{C}$ have equal numbers of friends, hence, so do $\mathrm{A}$ and $\mathrm{C}$.

The solution to this difficult problem requires great creative efforts. It does not use any familiar facts from the graph theory. Having considered the situation, the student himself is to think of the circumstances forcing the solution and find necessary arguments. Graphs are used only for argument visualization. But as it often happens, the visualization stimulates the solution.

Thus, finding other ways for problem solution and applying new content ideas stimulates using the earlier gained knowledge and skills in new situations, improves skills to see a familiar situation in a new problem. No doubt, it is the sign of creative activity in students.

Both the research and project activities give freedom of choice for one of the given criteria. Students need to feel the given freedom of choice and understand their participation in the teaching and learning process. However, the moment of their readiness for a new stage of activity is to be predicted. At first, students will have difficulties while performing their activities of the earlier described types and they are to get substantial help from the teacher. Gaining their experience, the students are enjoying the freedom of choice and, as a rule, expect less help from the teacher and get more and more interesting results from their activity.

4. If the student managed to get the results in the project and research learning activities at the level of personal achievements, it means that he is ready to do the projectresearch learning activity. Every student is supposed to choose both the organization and content by himself. The content of the project-research learning activity appears as the result of the creative task defined by the student on his own or with the help of the teacher. The organization is identified based on different types of the work carried out at the project stage. Its result is the class product with a new content (subjective in most aspects) and the structure achieved because of the student's free choice. As a rule, the project-research learning activity is conducted at the time of students' work on class projects. The class project is understood to be a set of different activities aimed at gaining knowledge and skills in the subject, organizing and creating a new product with the usage recommendations in one of the following ways: cumulative files, presentation, data base, video film, object model, etc.

There are some examples of the project- research learning activity performed by students when learning the topic "Graphs". They are the Euler theorem in practice; graph topology; matrices and graphs; graphs and labyrinths; graphs with color ribs; graph using to solve extreme solutions; graph on the chessboard; using the graph theory in number theory 
problems; graphs and programming; graphs and electric circuits; graphs and strategy games; using the graph theory in biology; how graphs help in chemistry; graphs and sports paradoxes; graphs in economics and management; graph theory and timetables, etc.

The most successful project in our practice turned out to be the project "How Graphs Help in Chemistry". The 12 slides of the project present chemical graphs (dichromatic, molecular, signaling, chemical-engineering) and describe the use of the Wiener index.

To sum up, developing mathematics learning activities and introducing creative activities for students while learning every thematic module has several stages. First, knowledge and skills are developed in the reproductive and productive activity when it's time to use inter-subject connections. Then, giving freedom of choice for either the content or the structure, the research and project activities are conducted simultaneously. Here, the necessity arises to use mathematical knowledge in different scientific and technical areas and to find new algorithms of the solution for familiar problems. The pinnacle of success is performing the project-research activity. Its content is closely connected with different branches of Math and other subjects.

The three types of students' learning activities implement the approaches for constructing the system of creativity-oriented problems. Being the main means of introducing creative activity for students, the problems determine the careful selection of the content.

\section{Discussions}

The problem of creativity and creative activities is one of the key problems in psychology and pedagogy. J. Hadamard (1970), D. B. Bogoyavlenskaya (2002), L. S. Vygotskiy (1997), G. Gilford (1965), V. N. Druzhinin (1999), V. A. Krutetskiy (1968), F. M. Matyushkin (1972), Y. A. Ponomarev (1976), teachers I. P. Volkov (1988), N. P. Guzik (1981), I. Y. Lerner (1974), G. I. Shukina (1986) and others studied this problem. They studied the theoretical model development of creative activity, interrelations between creative activity, consciousness and personality, the influence of the activity on the creativity development in a person, the psychological structure of a creative activity, the organization and conditions of successfully performing the creative activity.

Outstanding mathematicians V. I. Arnold (2008), B. V. Gnedenko (1979), R. Courant and H. Robbins (1967), H. Poincare (1983), A. Y. Hinchin (1989) outlined the significancy of the creative activity in Maths and in Maths teaching. Mathematical resource specialists G. D. Balk (1969), V. A. Gusev (2003), O. E. Episheva and V. I. Krupich (1990), G. Polya (1991) 
S. I. Schwarzbard (1964) and others, highlight the necessity to develop the creative activities in Math teaching at secondary schools and in school extra mathematics teaching.

The analysis of philosophical, psychological and pedagogical, and mathematical and methodical literature and the experience of Math teachers, shows that developing the creative activity in the Math teaching process in extra mathematics teaching is of great importance. The development of creative activities as one of the types of learning mathematics activities in extra mathematics teaching stimulates thinking processes, skills to find new solutions to problems, the ability to adapt to the changing class situation, productive and unconventional thinking and acting, performance, consciousness, and initiative at school.

However, the research on the mathematical theory and teaching methods has not considered the entire teaching concepts defining approaches to developing creative activities and giving the teaching techniques introducing creative mathematics activities for students in extra mathematics teaching. The reasons for that are the fragmentation of theoretical approaches and the objective complexity of developing the creative activity.

\section{Conclusion}

As follows from the analysis of different viewpoints on the matter of developing the creative and learning mathematics activities, the following types of learning mathematics activities in extra mathematics teaching have been classified: reproductive, productive, research, project, project-research. The position of creative learning mathematics activities is determined in them. The concept of developing creative learning mathematics activities in extra mathematics teaching have been worked out. The theory of developing creative learning mathematics activities conducting gradually reproductive, productive, research, project, project -research activities forms the base of the concept. Based on the concept, the methodological system has been worked out. The system contains its teaching objectives, content, methods, forms, and tools. According to the system, the approaches to constructing the system of creativity-oriented problems have been worked out. According to the approaches the system of creativity-oriented problems in the topic "Graphs" has been established. The pilot testing has proved a positive effect for the suggested teaching methods on the criteria of the creative activity for students. Quantitative and qualitative criteria of the tests used during the research have proved the effectiveness of the suggested teaching methods. All in all, applying the methodological system for developing the creative learning 
mathematics activities in extra mathematics teaching significantly improves the criteria of the creative activity in students.

\section{Recommendations}

The article materials may be interesting for practical teachers and tutors for their students to increase the level of achieving creative results and also to estimate and, if necessary, to correct the personal teaching process while learning Mathematics. Considering the results of the research, the following scientific problems and prospective lines of the development are to be considered in the future: refining and explaining some concepts connected with developing the psychological and teaching potential of applying problem systems in the educational process and ensuring development of the five types of learning activities: reproductive, productive, research, project, project-research.

\section{Acknowledgments}

The work is performed according to the Russian Government Program of Competitive Growth of Kazan Federal University

\section{References}

BALK, G. D. Concerning Applying Heuristic Devices in School Mathematics Teaching.

Mathematics at School, n. 5, p. 21-28, 1969.

BOGOYAVLENSKAYA, D. B. Psychology of Creative Abilities. 1st ed. Mocsow: Academy, 2002. $320 \mathrm{p}$.

COURANT, R. \& ROBBINS, H. What is Mathematics? 2nd ed. Moscow: Prosvesheniye, 1967. 560 p.

Development Concept of Mathematical Education in the Russian Federation. Rossiyskaya Gazeta, n. 6270, p. 10. Disponible in: <http://www.rg.ru/2013/12/27/matematika-site-dok.html>. Acess in: 27 dec. 2013.

DRUZHININ, V. N. Psychology of General Abilities. 1st ed. Saint-Petersburgh: Peter, 1999. 368 p.

EPISHEVA, O. E.; KRUPICH, V. I. To Teach School Students to Learn Mathematics: Developing Methods of Learning Activity. 1st ed. Moscow: Prosvesheniye, 1990. 128 p.

GILFORD, G. Three Sides of Intelligence. Psychology of Thinking. Ed. A. M. Matyushkin. 1st ed. Moscow: Progress, 1965. p. 433-456.

GNEDENKO, B. V. Concerning Mathematical Creativity. Mathematics at School, n. 6, p. 16-22, 1979. 
GOREV, P. M. \& UTEMOV, V. V. Classes of Developing Mathematics. 5-6 Forms: Problems of the Mathematics Study Group. 1st ed. Kirov: MCITO Press, 2014. 207 p.

GOREV, P. M. Introducing Mathematical Creativity: Extra Mathematics Teaching. 1st ed. Saarbrucken: Lambert Academic Publishing, 2012. 156 p.

GUSEV, V. A. Psychological and Pedagogical Bases of Mathematics Teaching. 1st ed. Moscow: Verbum-M, Academy, 2003. 432 p.

GUZIK, N. P. To Teach how to Learn. 1st ed. Moscow: Pedagogika, 1981. 88 p.

HADAMARD, J. Research on Psychology of Invention Process in Mathematics. 1st ed. Mocsow: Sovetskoye Radio, 1970. 152 p.

HINCHIN, A. Y. Concerning Educational Effect of Mathematics Classes. Effectiveness Increase of Teaching Maths at School. Ed. G. D. Gleyzer. 1st ed. Moscow: Prosvesheniye, 1989. p.18-37.

IBRAGIMOV, I. D. et al. Recommendations on the Textbooks Creation as Information and Teaching Tools of Education Management. International Electronic Journal of Mathematics Education, LOOK Academic Publishers, v. 11, n. 3, p. 433-446, 2016.

KAMALOVA, L. A.; RAYKOVA, E. The Quality and Criteria of Evaluation of Educational Work at the Universities of Russia at the Contemporary Stage. International Electronic Journal of Mathematics Education, LOOK Academic Publishers, v. 11, n. 1, p. 71-79, 2016.

KRUTETSKIY, V. A. Psychology of Mathematical Abilities in Students. 1st ed. Moscow: Prosvesheniye, 1968. $431 \mathrm{p}$.

LERNER, I. Y. Problem-Based Learning. 1st ed. Moscow: Znaniye, 1974. 64 p.

MATYUSHKIN, A. M. Problem Situations in Thinking and Education. 1st ed. Moscow: Pedagogika, 1972. 208 p.

POINCARE, H. Concerning Science. 1st ed. Moscow: Nauka, 1983. 736 p.

POLYA, G. How to Solve a Problem. 1st ed. Lvov: Kvantor, 1991. 216 p.

PONOMAREV, Y. A. Psychology of Creativity and Teaching. 1st ed. Moscow: Pedagogika, 1976. $280 \mathrm{p}$.

ŞANDIR, H. and AZTEKIN, S. Pre-Service Math Teachers' Opinions about Dynamic Geometry Softwares and Their Expectations from Them. International Electronic Journal of Mathematics Education, LOOK Academic Publishers, v. 11, n. 3, p. 421-431, 2016.

SCHWARZBARD, S. I. Concerning Stimulating Interests, Vocation and Abilities in Students for Mathematics. Mathematics at School, n. 6, p. 32-37, 1964.

SHUKINA, G. I. The Role of Activity in the Learning Process. 1st ed. Moscow: Prosvesheniye, 1986. $142 \mathrm{p}$.

VOLKOV, I. P. Teaching Creativity. 1st ed. Moscow: Pedagogika, 1988. 96 p.

VYGOTSKIY, L. S. Imagination and Creativity at an Early Age. 1st ed. Saint Petersburgh: Soyuz, 1997. $96 \mathrm{p}$. 
Submetido em Junho de 2016. Aprovado em Dezembro de 2016. 